\title{
PRINCIPAIS DESAFIOS E OPORTUNIDADES PARA A GESTÃO MEDIANTE A PANDEMIA GERADA PELA COVID-19: UMA ANÁLISE NA REGIÃO DE SÃO JOSÉ DO RIO PRETO - SP
}

\section{ARTIGO ORIGINAL}

PASSERINI, Marcos Levi ${ }^{1}$, CALVO, Erica Pavi², SEGANTIN, João Angelo³

PASSERINI, Marcos Levi. CALVO, Erica Pavi. SEGANTIN, João Angelo. Principais desafios e oportunidades para a gestão mediante a pandemia gerada pela COVID-19: uma análise na região de São José do Rio Preto - SP. Revista Científica Multidisciplinar Núcleo do Conhecimento. Ano. 06, Ed. 11, Vol. 07, pp. 116-134. Novembro 2021. ISSN: 2448-0959, Link de acesso: https://www.nucleodoconhecimento.com.br/administracao/desafios-e-oportunidades, DOI: 10.32749/nucleodoconhecimento.com.br/administracao/desafios-eoportunidades

\section{RESUMO}

A Pandemia gerada pela COVID-19 tem provocado mudanças no modo de vida da população, alterando alguns costumes e criando outros, e com suas consequências potencializadas, em parte pela instabilidade política e econômica na qual o país já vinha enfrentando, centenas de micro e pequenas empresas, e até mesmo algumas de grande porte, fecharam suas portas, resultando, assim, no aumento do desemprego. Desse modo, muitas pessoas tiveram que se reinventar para manter seu empreendimento aberto ou até mesmo garantir o sustento de suas famílias durante a pandemia. Algumas até conseguiram aumentar seus lucros com novas oportunidades de negócios. Neste contexto, o presente artigo tem como objetivo apresentar os principais desafios e oportunidades para a gestão empresarial em virtude da pandemia gerada pelo COVID-19 na região de São José do Rio Preto -

\footnotetext{
${ }^{1}$ Graduação.

${ }^{2}$ Graduação.

${ }^{3}$ Orientador.

RC: 101267

Link de acesso: https://www.nucleodoconhecimento.com.br/administracao/desafiose-oportunidades
} 
SP. Realizado por meio de uma pesquisa bibliográfica e visando confrontar a teoria e a prática com uma pesquisa de campo feita de forma online, respeitando os critérios de distanciamento da OMS, o presente artigo identifica como a sociedade localizada na região São José do Rio Preto, no interior de São Paulo, tem lidado com tal situação e destaca o protagonismo feminino frente às dificuldades encontradas.

Palavras-chave: Gestão, Crise, Desafios, Oportunidades.

\section{INTRODUÇÃO}

No ano de 2020, viveu-se um cenário nacional e mundial assustador devido a pandemia e o caos gerado pela COVID-19, devido ao surgimento do vírus SARSCov-2, popularmente chamado de "novo Coronavírus".

A pandemia impactou profundamente a vida das pessoas, transformando radicalmente seu cotidiano, hábitos e atitudes, ainda mais com o isolamento social, no qual o ser humano da atualidade não está acostumado a viver.

Os impactos sociais, econômicos, políticos, culturais, são enormes. Alguns apresentam consequências desastrosas e sem volta. Entre eles, o impacto principal e mais doloroso é o impacto da perda da vida humana.

E como preservar a vida, manter a saúde mental e ainda sustentar a economia do lar e ter acesso a bens essenciais como alimentação, remédios, sistema de saúde, transportes e educação? Esses são desafios que a população precisa enfrentar para sobreviver ao caos que se vivencia.

Porém, é justamente diante das adversidades que surgem as oportunidades, mesmo sendo um desafio encontrá-las. Dessa forma, o presente trabalho busca identificar como as pessoas estão administrando e reagindo aos desafios e as possíveis oportunidades diante da situação caótica atual sem precedentes.

RC: 101267

Link de acesso: https://www.nucleodoconhecimento.com.br/administracao/desafiose-oportunidades 
O presente artigo tem como objetivo apresentar os principais desafios e oportunidades para a gestão empresarial em virtude da pandemia gerada pelo COVID-19 na região de São José do Rio Preto - SP.

\section{METODOLOGIA}

Fonseca (2002) explica o significado de metodologia por meio de sua origem etimológica:

[...] methodos significa organização, e logos, estudo sistemático, pesquisa, investigação; ou seja, metodologia é o estudo da organização, dos caminhos a serem percorridos, para se realizar uma pesquisa ou um estudo, ou para se fazer ciência. Etimologicamente, significa o estudo dos caminhos, dos instrumentos utilizados para fazer uma pesquisa científica (FONSECA, 2002).

Assim, para o desenvolvimento do presente trabalho, fora utilizado a pesquisa bibliográfica, que, de acordo com Gil (2010), é a pesquisa levantada com apoio de bibliografia já publicada em forma de livros, periódicos, teses, jornais, anais de congresso etc., que proporciona ao pesquisador acesso a materiais já produzidos sobre o assunto a ser estudado.

Porém, visando confrontar a teoria com a prática, foi realizada uma pesquisa de campo, que, segundo Gil (2010), corresponde a uma realidade vivenciada de uma situação, pois é realizada com base nas ações, atitudes ou pensamentos de um grupo específico, que será questionado para que informem o que ocorre naquela realidade específica.

Quanto à abordagem do problema, a presente pesquisa é desenvolvida pelo método quantitativo, que, de acordo com Richardson (1999), tem como característica os resultados numéricos do estudo proposto, para analisar o comportamento e opinião dos indivíduos de um determinado grupo.

A coleta de dados, realizada durante o período da pandemia, ocorreu de forma online, como maneira de evitar o contato físico e respeitar o isolamento social. Ela 
se deu por meio de um questionário com 14 questões de múltipla escolha, através do portal Survio.

O questionário foi divulgado por meio das mídias sociais, do envio direto por WhatsApp, pela página no Facebook do Monte Aprazível Notícias "O portal da cidade aprazivelense", da Rádio Difusora Aparecida 105,7 FM de Monte Aprazível e da FAECA Dom Bosco de Monte Aprazível.

\section{DESENVOLVIMENTO}

\subsection{GESTÃO}

Segundo o dicionário Dicio (s.d), a palavra "gestão" significa: "s.f". Ação de gerir, de administrar, de governar ou de dirigir negócios públicos ou particulares". Pode-se dizer, então, que, na administração, a gestão, é vista como um meio de organização que pode ser aplicado em diversas áreas, sejam elas pública, privada ou mistas, tem como principal tarefa, por meio de gestores, conduzir equipes, setores e grupos a alçarem o máximo desempenho dentro de um processo, evitando desperdícios.

\subsection{CRISE}

A palavra "crise" corresponde a uma mudança brusca ou alteração não esperada de uma situação, um ambiente ou uma normalidade vivida regularmente, que precisa de medidas e soluções imediatas e urgentes.

Segundo Luecke (2007):

Crise é uma mudança repentina ou gradual que resulta em um problema urgente que deve ser abordado imediatamente. Para uma empresa, uma crise representa qualquer coisa com potencial de causar danos súbitos e graves a seus funcionários, a sua reputação ou a seu resultado financeiro (LUECKE, 2007).

Assim, tem-se que crise é um evento danoso, na maioria das vezes imprevisível, que pode ter as mais variadas origens e que, se não administrada e conduzida de forma

RC: 101267

Link de acesso: https://www.nucleodoconhecimento.com.br/administracao/desafios- 
adequada, pode resultar em sérios prejuízos para uma empresa, para as pessoas e para a sociedade no geral, que é exatamente o que se observa com o COVID-19.

\subsection{PANDEMIA}

De acordo com a OMS (2020), "[...] uma pandemia é a disseminação mundial de uma nova doença. O termo é utilizado quando uma epidemia - grande surto que afeta uma região - se espalha por diferentes continentes com transmissão sustentada de pessoa para pessoa."

A OMS (2020), ao definir pandemia, não aborda a questão da gravidade de uma doença, mas apenas o aspecto geográfico da rápida disseminação. As pessoas, instituições, governos e o mundo, de forma geral, não estão preparados para enfrentar uma pandemia, visto que ela chega de forma sorrateira e imprevisível, causando pânico, desespero e caos. A doença do COVID-19 tem mostrado isso claramente no Brasil, e na região Noroeste Paulista não tem sido diferente.

\subsection{DESAFIOS}

Os desafios surgem constantemente na vida do ser humano. Se pesquisado no dicionário, são vários os conceitos de desafio, como chamamento para um torneio, incentivo de fazer algo que se tem dificuldade, peleja, luta etc. $O$ desafio é um objetivo a ser cumprido, que pode ser encarado como uma meta ou um plano de ação a ser executado, em que se propõe a desafiar os obstáculos para cumpri-los.

A pandemia do COVID-19 claramente está sendo um desafio e mostrando que muitos estão se sobressaindo, mas outros, infelizmente, estão sucumbindo.

\subsection{O QUE SÃO OPORTUNIDADES?}

A palavra "oportunidade", segundo o dicionário Dicio (s.d), significa: "Característica, condição do que é oportuno, no momento adequado. Circunstância favorável para

RC: 101267

Link de acesso: https://www.nucleodoconhecimento.com.br/administracao/desafiose-oportunidades 
que alguma coisa aconteça; [...] Situação que convém ou é apropriada para circunstância oportuna."

Oportunidade é um momento oportuno, um contexto (ainda que numa situação ruim) que se revela para que algo aconteça naquela situação, apresenta uma chance, um benefício de conquista e crescimento.

\subsection{REGIÃO DE SÃO JOSÉ DO RIO PRETO}

A região de São José do Rio Preto é a 8o região administrativa do Estado de São Paulo. Localizada no extremo noroeste do Estado, é formada por 96 municípios distribuídos em 5 (cinco) regiões de governo. Tem quase 1.500.000 habitantes e uma área de mais de $25.000,00 \mathrm{Km}^{2}$. Como se trata de uma das maiores regiões do Estado, foi resolvido estreitar a pesquisa, abrangendo as cidades nas quais se tem alunos cursando graduação na FAECA Dom Bosco, que são 22 cidades:

Quadro 1 - Cidades Alvos da Pesquisa

\begin{tabular}{|l|l|l|l|}
\hline Adolfo & Macaubal & Nhandeara & São José do Rio Preto \\
\hline Cosmorama & Magda & Nipoã & Sebastianópolis do Sul \\
\hline $\begin{array}{l}\text { Floreal } \\
\text { Gastão } \\
\text { Vidigal }\end{array}$ & Mendonça & Nova Aliança & Tanabi \\
\hline Jaci & Monte Aprazível & Planalto & União Paulista \\
\hline $\begin{array}{l}\text { José } \\
\text { Bonifácio }\end{array}$ & Neves Paulista & Poloni & \\
\hline
\end{tabular}

Fonte: Autor, 2020. 


\section{RESULTADOS}

A pesquisa foi realizada nas cidades citadas no quadro 1, por meio do link (https://www.survio.com/survey/d/pesquisa-faeca-dombosco-2020), disponibilizado por WhatsApp, pela página no Facebook do Monte Aprazível Notícias "O portal da cidade aprazivelense", pela Rádio Difusora Aparecida 105,7 FM e pela FAECA Dom Bosco, todos de Monte Aprazível/SP.

O questionário foi respondido por 108 pessoas, entre as quais: $64,2 \%$ eram do sexo feminino, 42,2\% se encontravam na faixa etária de 18 aos 29 anos e mais de 50\% do público possui uma formação de nível superior em nível de pós-graduação.

Gráfico 1 - Sexo dos participantes

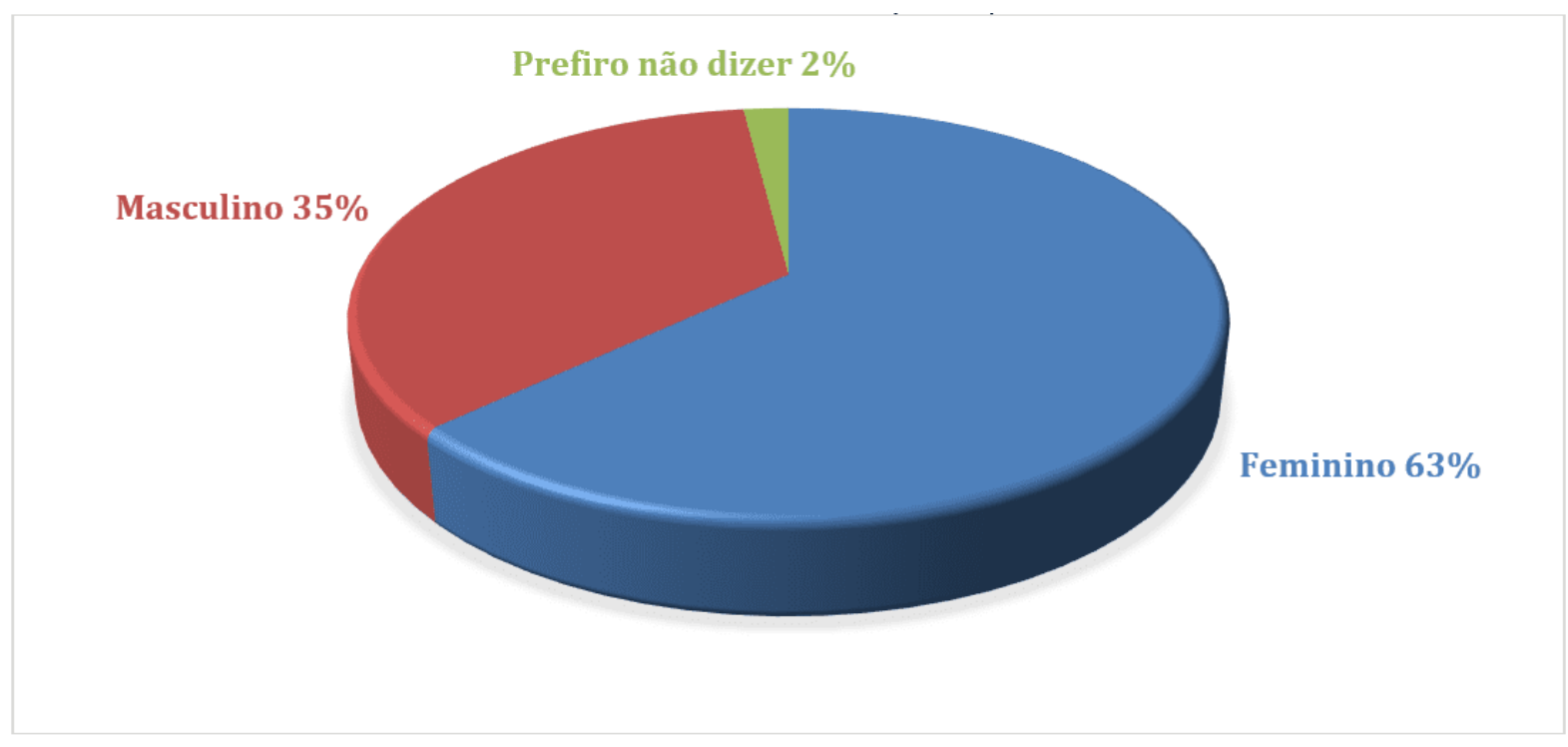

Fonte: Autor, 2020.

RC: 101267

Link de acesso: https://www.nucleodoconhecimento.com.br/administracao/desafiose-oportunidades 
Gráfico 2 - Faixa Etária dos participantes

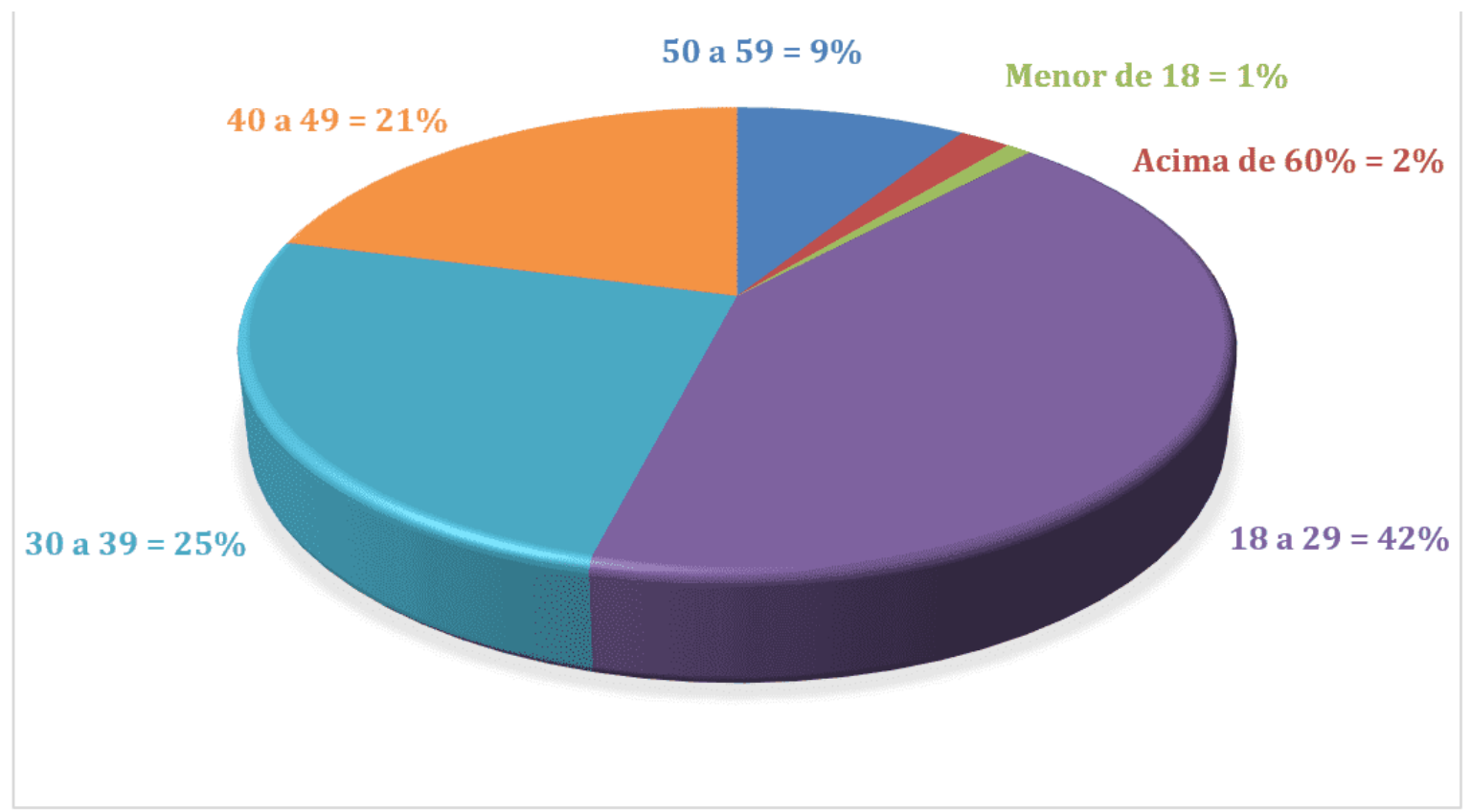

Fonte: Autor, 2020.

Gráfico 3 - Nível de Instrução

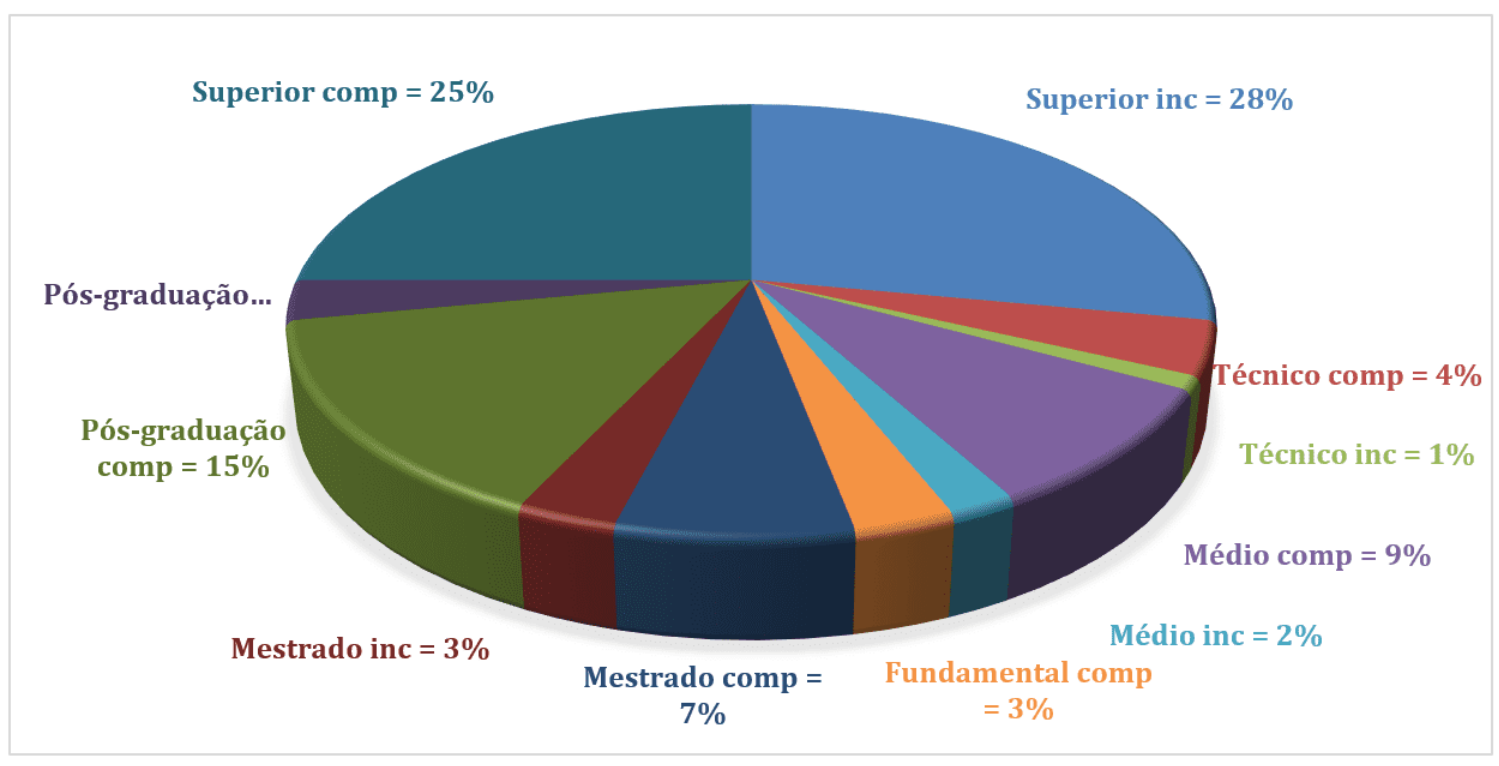

Fonte: Autor, 2020.

RC: 101267

Link de acesso: https://www.nucleodoconhecimento.com.br/administracao/desafiose-oportunidades 
Gráfico 4 - Ocupação profissional pré Covid-19

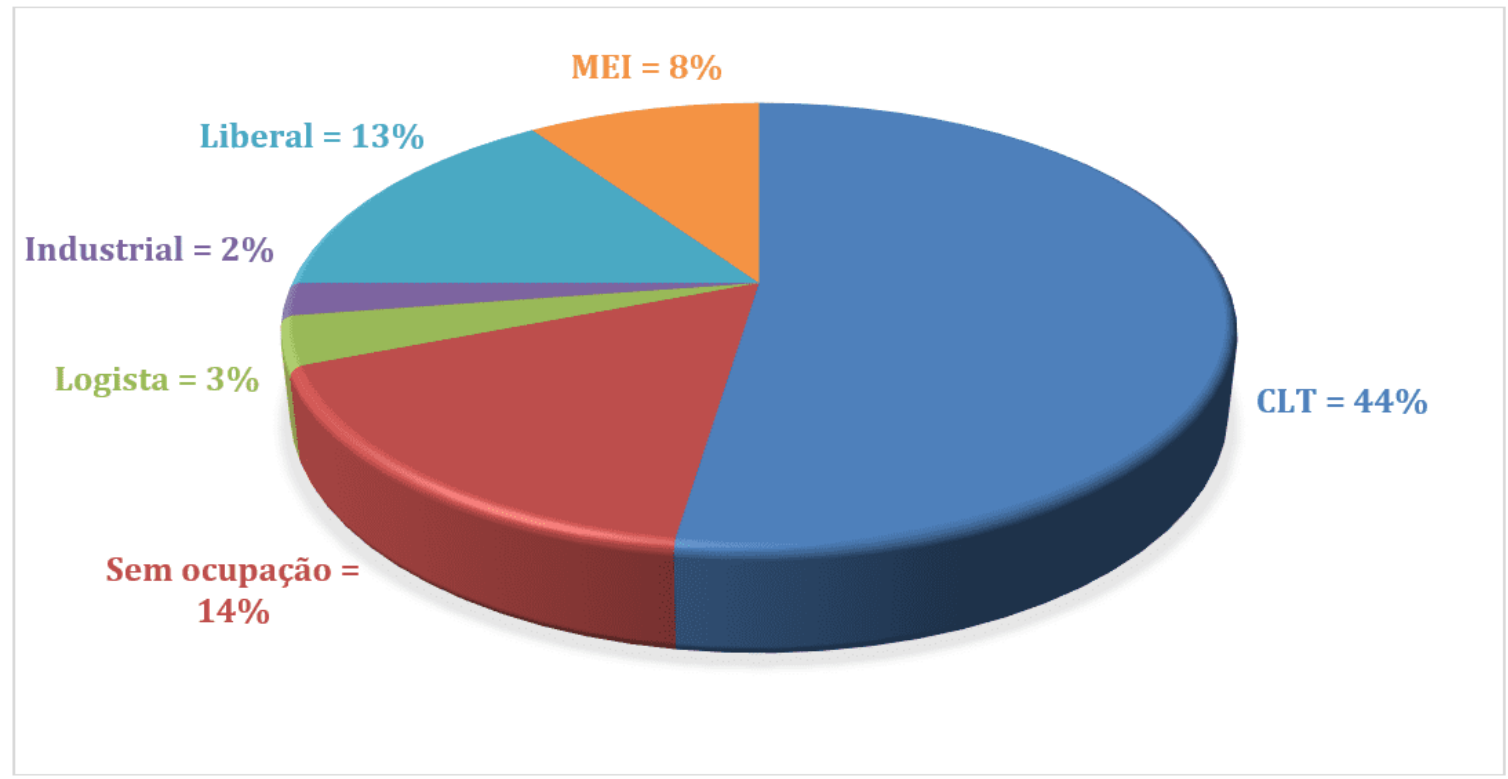

Fonte: Autor, 2020.

A pesquisa apontou que $45 \%$ dos entrevistados exerciam atividade com registro em carteira antes da pandemia; $26,7 \%$ eram profissionais liberais ou empresários; $16,5 \%$ exerciam trabalho sem o devido registro e 14,7\% não possuíam uma ocupação profissional. O que, diante dos elevados números de desemprego no Brasil, mesmo antes da pandemia, não é um resultado tão assustador, visto que quase $50 \%$ dos entrevistados estavam empregados em regime celetista.

Quando questionados sobre a necessidade de tomar medidas extremas, com demissão de funcionários ou redução de despesas, mais de $84 \%$ responderam que não possuíam funcionários ou que apenas reduziram as despesas; e, ainda, mais de $57 \%$ responderam não terem solicitado nenhum benefício ou ajuda financeira de qualquer natureza. Esses resultados mostram que, entre o público pesquisado, o cenário da pandemia não causou muitas mudanças. 
Gráfico 5 - Tomou medidas extremas para a redução de despesas

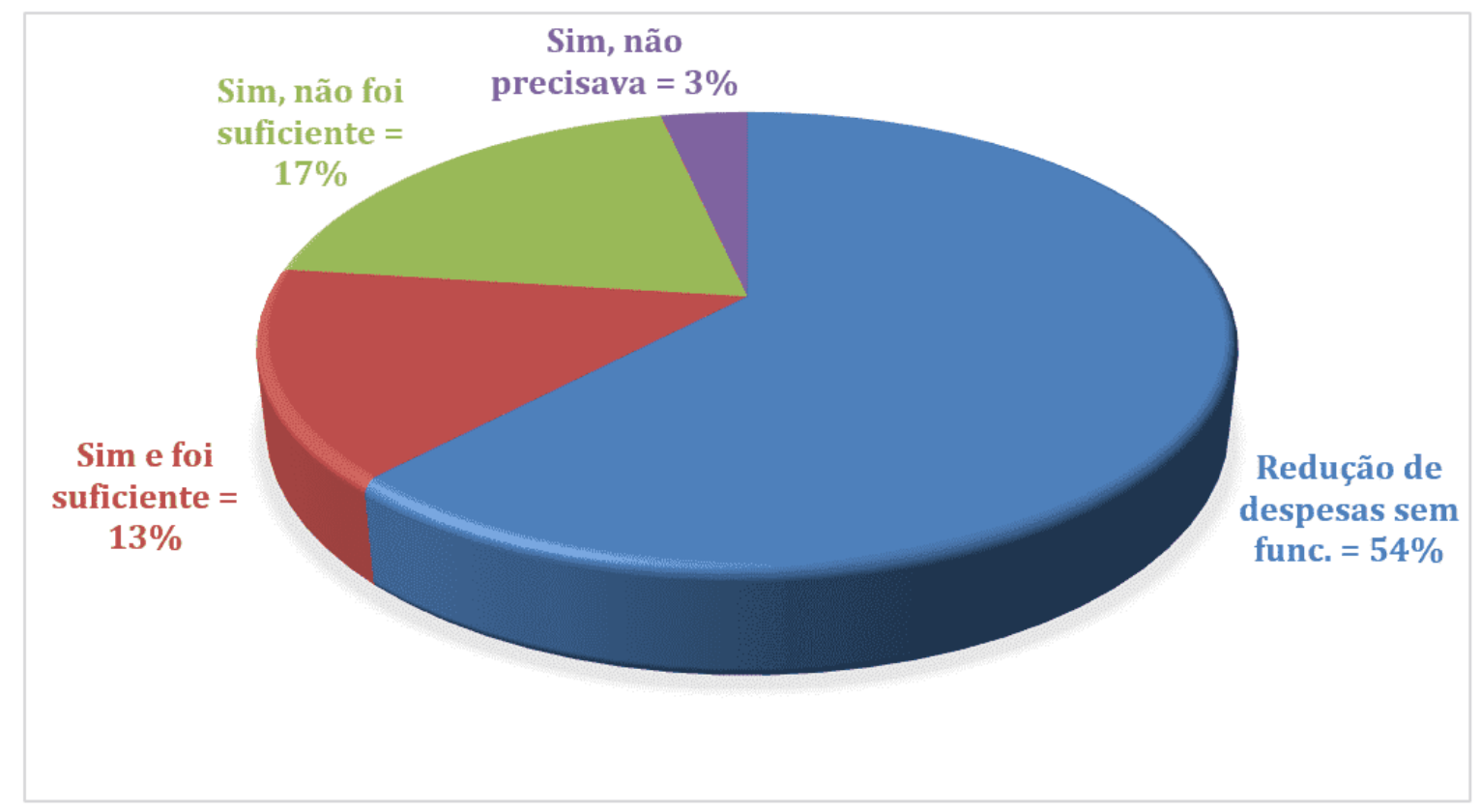

Fonte: Autor, 2020.

Gráfico 6 - Solicitou algum benefício ou ajuda financeira no período? Foi suficiente?

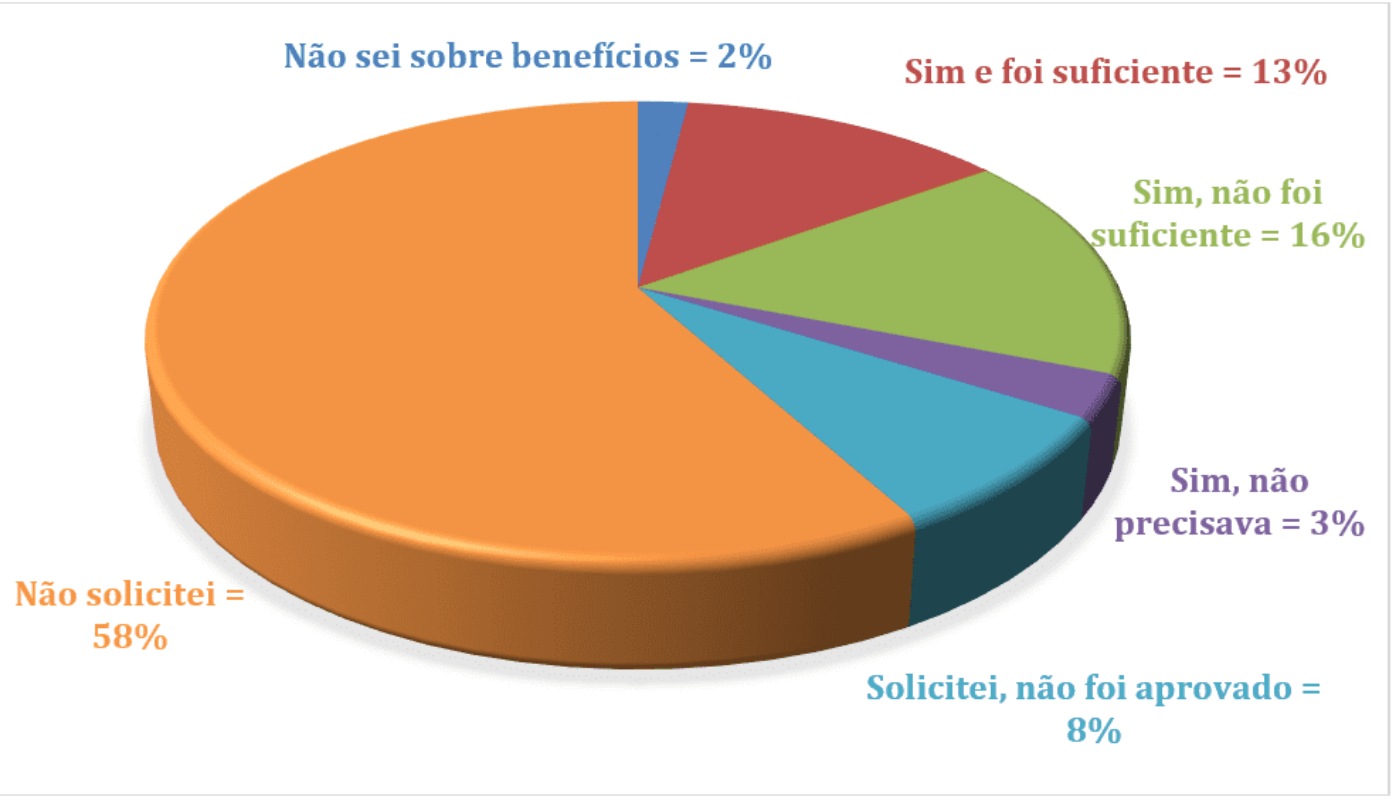

Fonte: Autor, 2020.

RC: 101267

Link de acesso: https://www.nucleodoconhecimento.com.br/administracao/desafiose-oportunidades 
Sobre implementar novas maneiras de obtenção de lucro ou renda para compensar as perdas do início da pandemia, mais de $61,4 \%$ disseram não ter implementado nada; $15,6 \%$ responderam que sim, mas só conseguindo cobrir as perdas; e outros $15,6 \%$ responderam que sim, implementaram, compensaram as perdas e ainda obtiveram lucro. Esses dados são similares aos dos resultados acima, em que, como consequência do número de empregados em regime celetista e de profissionais liberais/empresários, algumas empresas conseguiram manter seu rendimento, mesmo com um surto pandêmico instaurado.

Quando questionados sobre conseguir empreender dentro da sua área profissional, com novas ideias e práticas que poderiam melhorar o processo produtivo, aumentando lucro ou reduzindo as despesas durante a pandemia, 33\% disseram que sim, tinham liberdade para empreender; quase 30\% responderam que sim, mas que sem muita liberdade para tanto ou que seria necessário ajuda e 38,5\% responderam que não, que a área não permite empreender ou que não é necessário.

Quando foram perguntados se buscariam por oportunidades de empreender em novos negócios, ao saber que após a pandemia haveria lacuna por produtos e serviços, mais de $25 \%$ responderam que não, que estão bem do jeito que estão ou que não tem vontade de empreender e 22,9\% responderam que sim, e que já estariam trabalhando nisso. 
Gráfico 7 - Implementaram novas maneiras de obter lucro ou renda

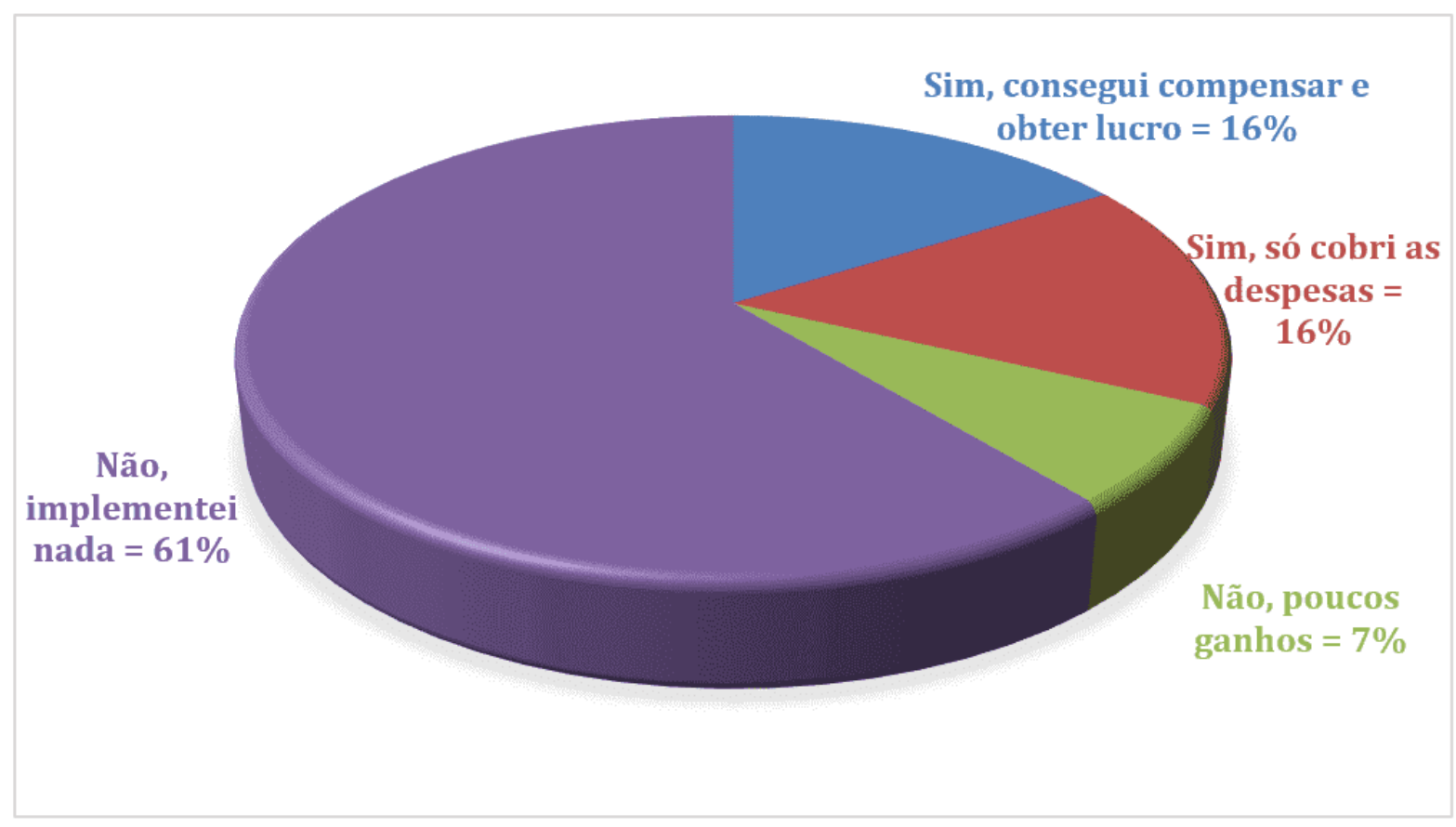

Fonte: Autor, 2020.

Gráfico 8 - Conseguiram empreender em sua área profissional. Aumentaram o lucro ou reduziram as despesas

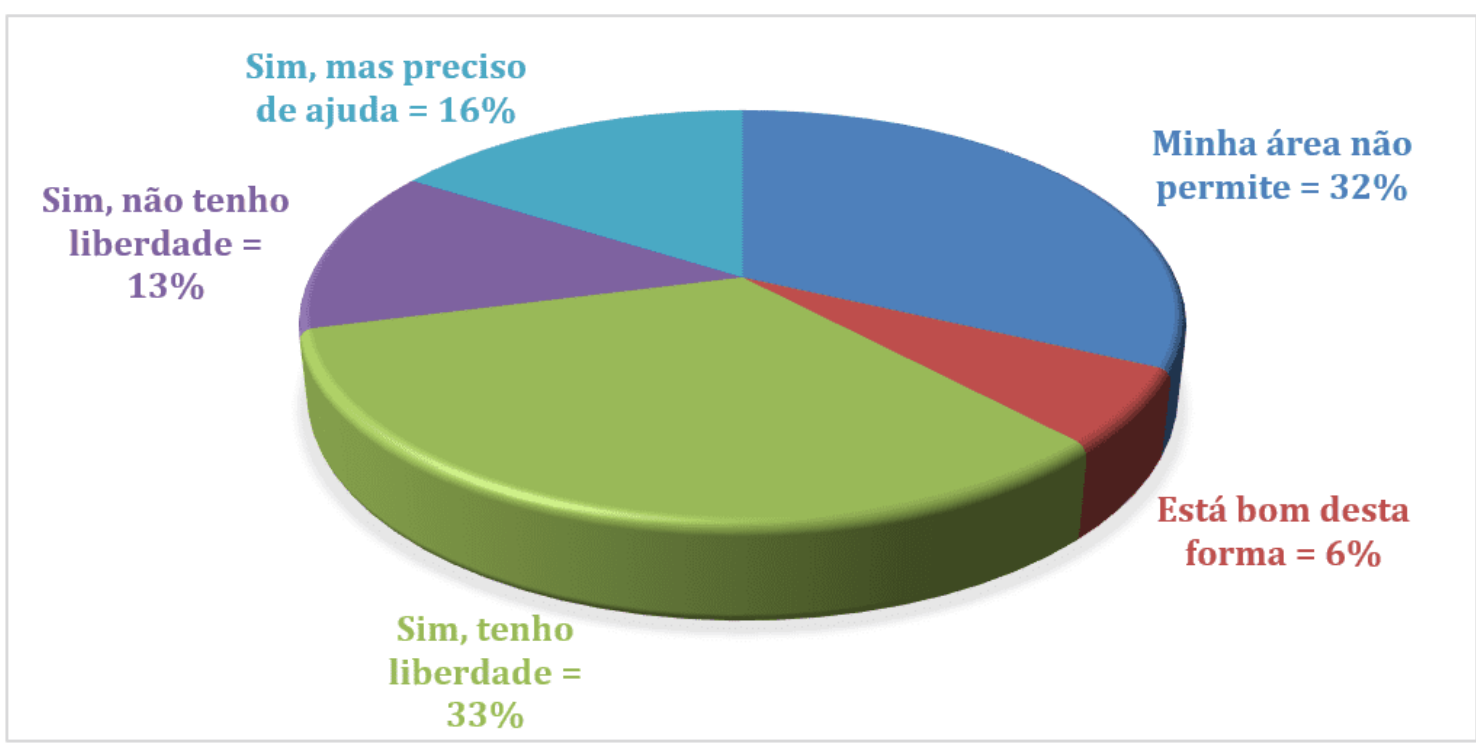

Fonte: Autor, 2020.

RC: 101267

Link de acesso: https://www.nucleodoconhecimento.com.br/administracao/desafiose-oportunidades 
Gráfico 9 - Após este período da pandemia buscarão oportunidades de empreender

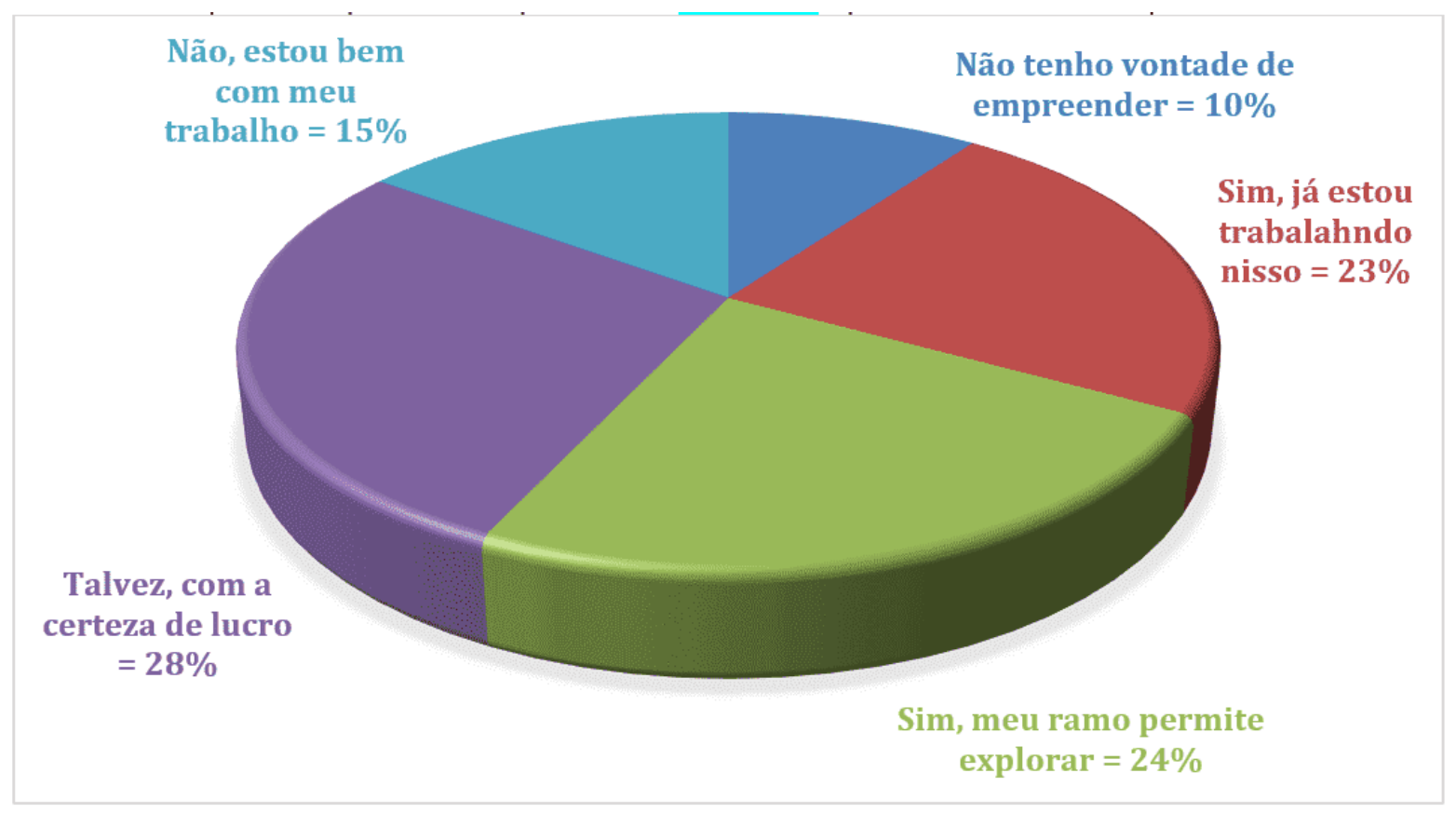

Fonte: Autor, 2020.

Com relação ao perfil profissional, $57,8 \%$ dos entrevistados disseram ser dinâmicos e coletivos, enquanto $14,7 \%$ disseram ser quietos e individualistas. $67 \%$ dos entrevistados avaliaram-se como ótimo ou bom em sua capacidade de adaptar (resiliência) diante das circunstâncias atuais e $23 \%$ avaliaram sua capacidade como regular ou ruim. Já na avaliação própria, sobre se colocar no lugar do outro (empatia), o resultado foi de $93,6 \%$.

Tais resultados mostram muito positivismo, o que reflete uma característica do povo brasileiro, de prestar socorro e ser acolhedor nos momentos difíceis, como em calamidades e pandemias.

RC: 101267

Link de acesso: https://www.nucleodoconhecimento.com.br/administracao/desafiose-oportunidades 
Gráfico 10 - Você tem perfil dinâmico e coletivo ou mais quieto e individual

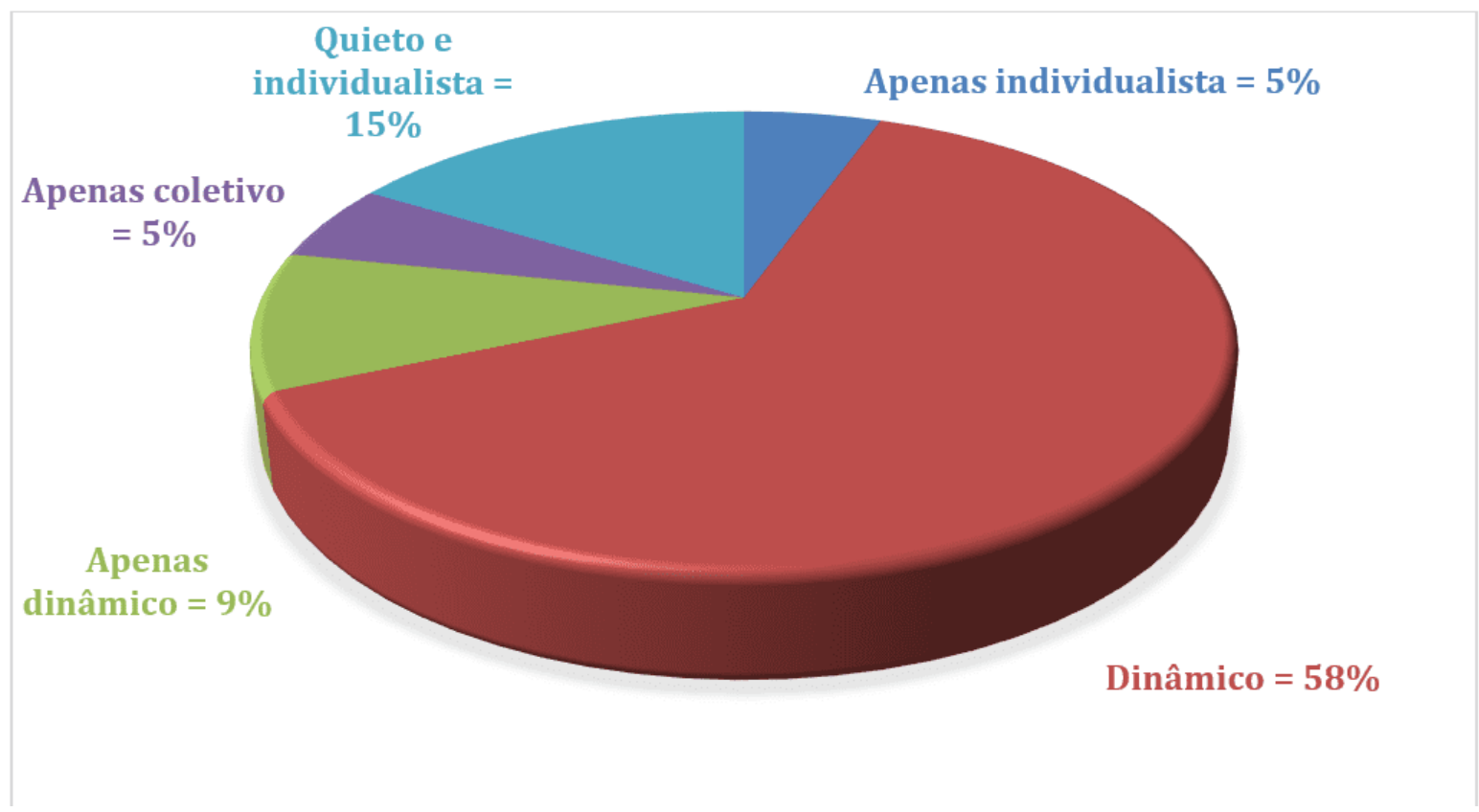

Fonte: Autor, 2020

Gráfico 11 - Sua capacidade de se adaptar

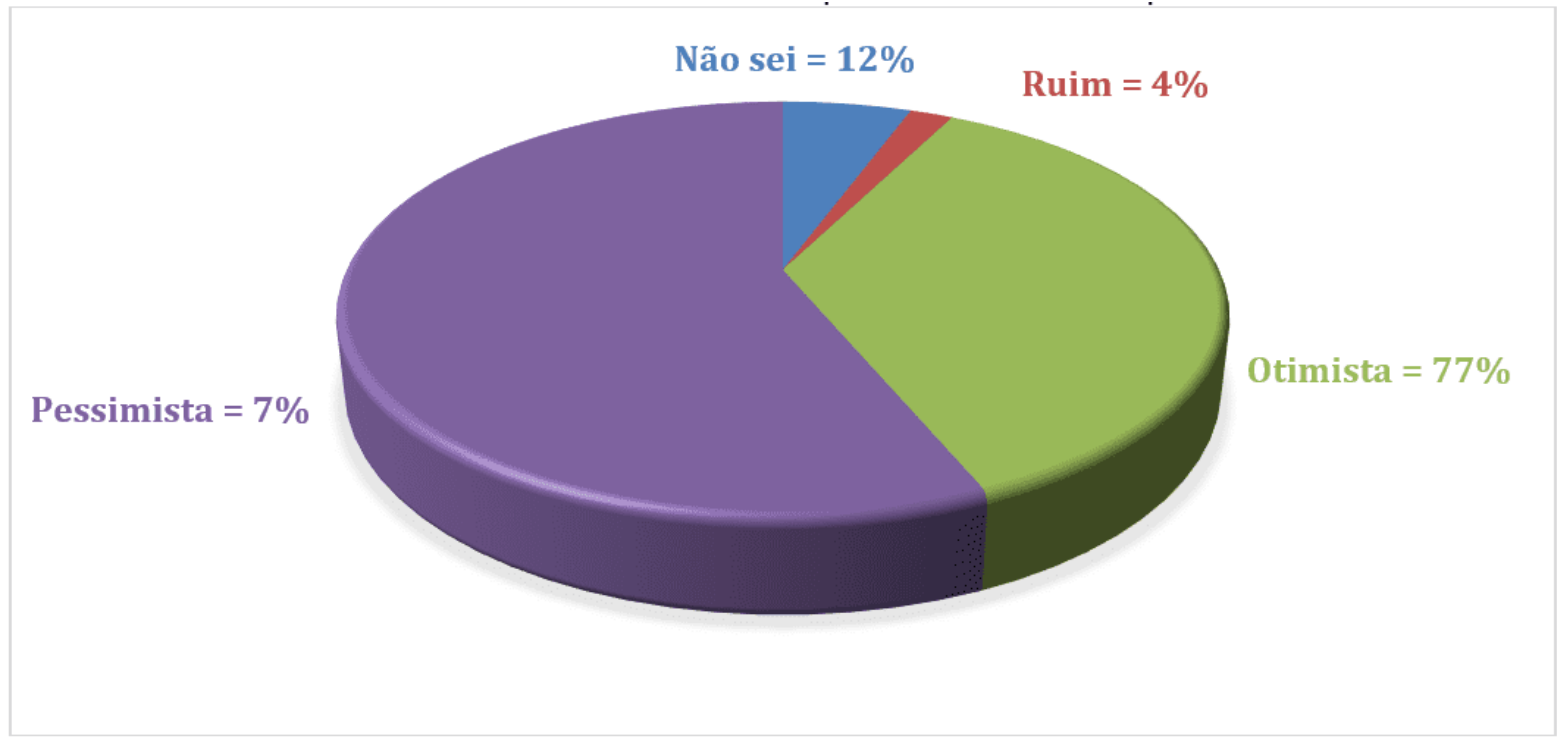

Fonte: Autor, 2020.

RC: 101267

Link de acesso: https://www.nucleodoconhecimento.com.br/administracao/desafiose-oportunidades 
Gráfico 12 - Sua capacidade de se colocar no lugar do outro neste momento

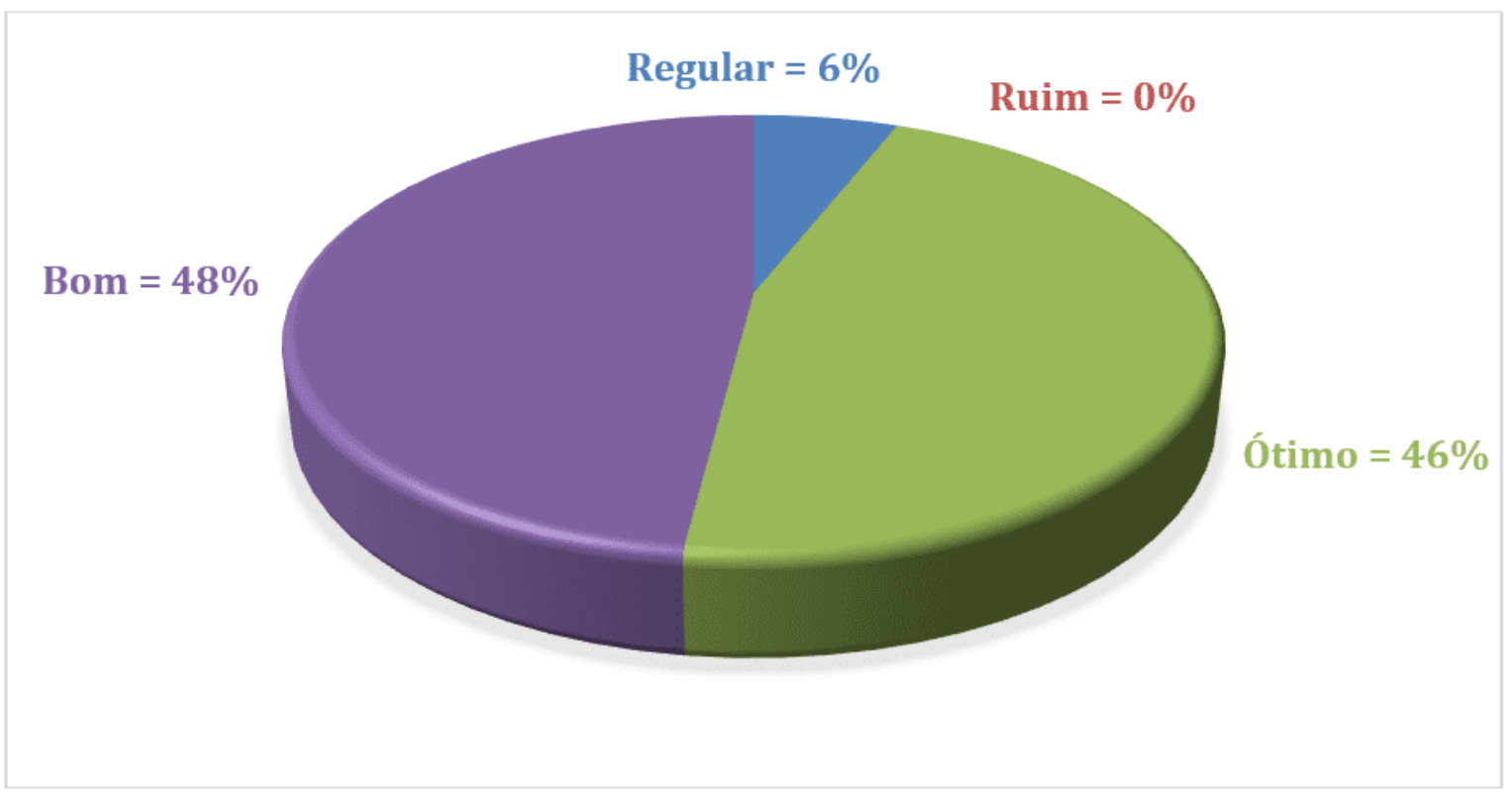

Fonte: Autor, 2020.

A pandemia gerada pela COVID- 19 afetou o mundo de diversas formas, alguns de forma avassaladora e outros nem tanto. Mas o fato é que todos foram afetados, tendo suas vidas e hábitos transformados, talvez sem retorno de como era antes. Tanto que, na pesquisa, apenas $9,2 \%$ dos entrevistados acreditam que tudo voltará à normalidade com o fim da pandemia.

Quase metade dos entrevistados - 47,7\% - acreditam que as coisas voltarão ao normal, mas não como eram antes. E 22,9\% acreditam que nada será como antes. Apesar de um leve pessimismo inserido nessa resposta, quando perguntados sobre o futuro, $80,9 \%$ se dizem otimistas, refletindo um positivismo de que haverá uma busca por maneiras de se adaptar e se encaixar em um novo modo de vida. 
Gráfico 13 - Passado a tensão da COVID-19, tudo voltará a normalidade

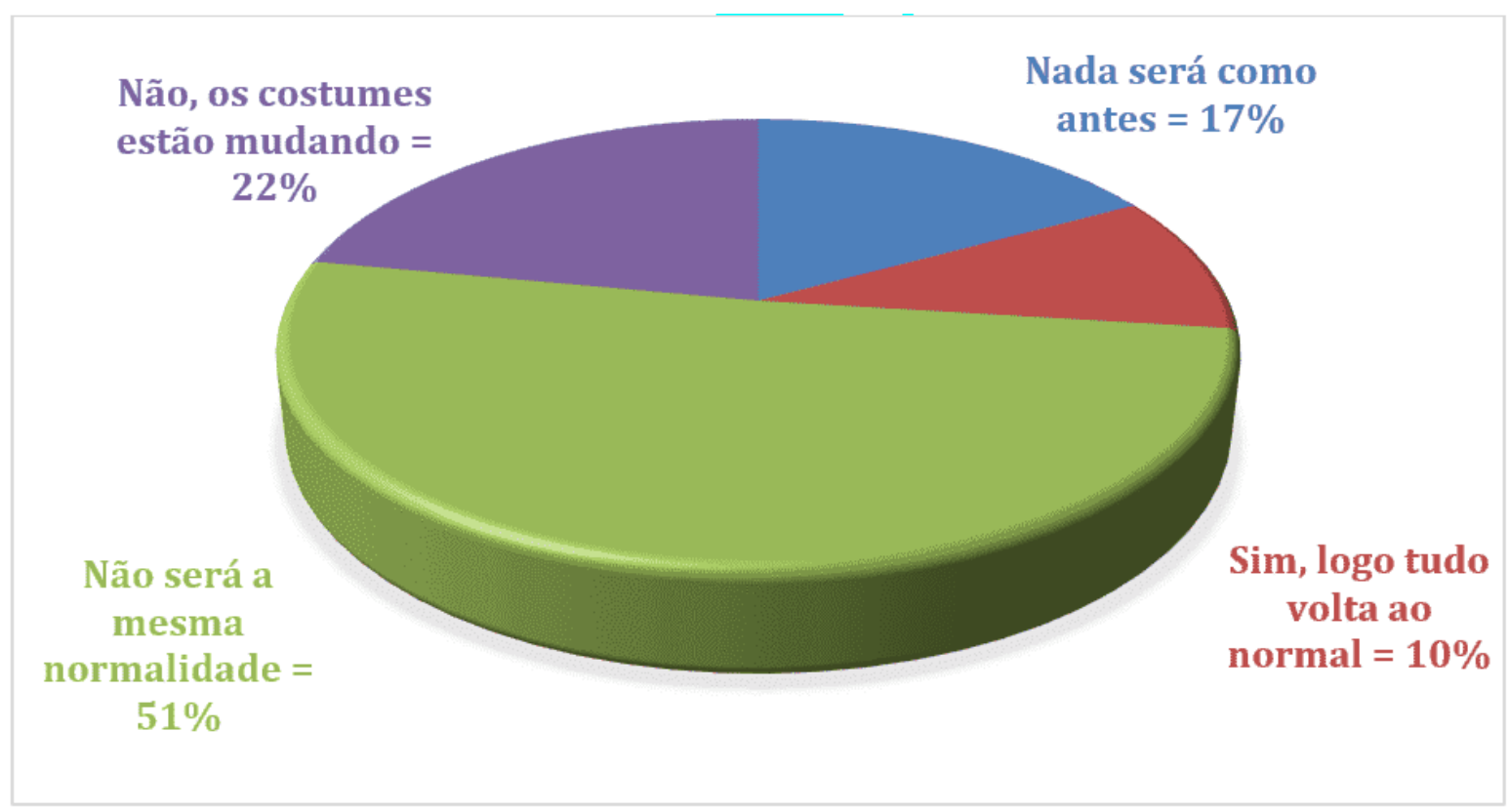

Fonte: Autor, 2020

Gráfico 14 - Opinião sobre o futuro

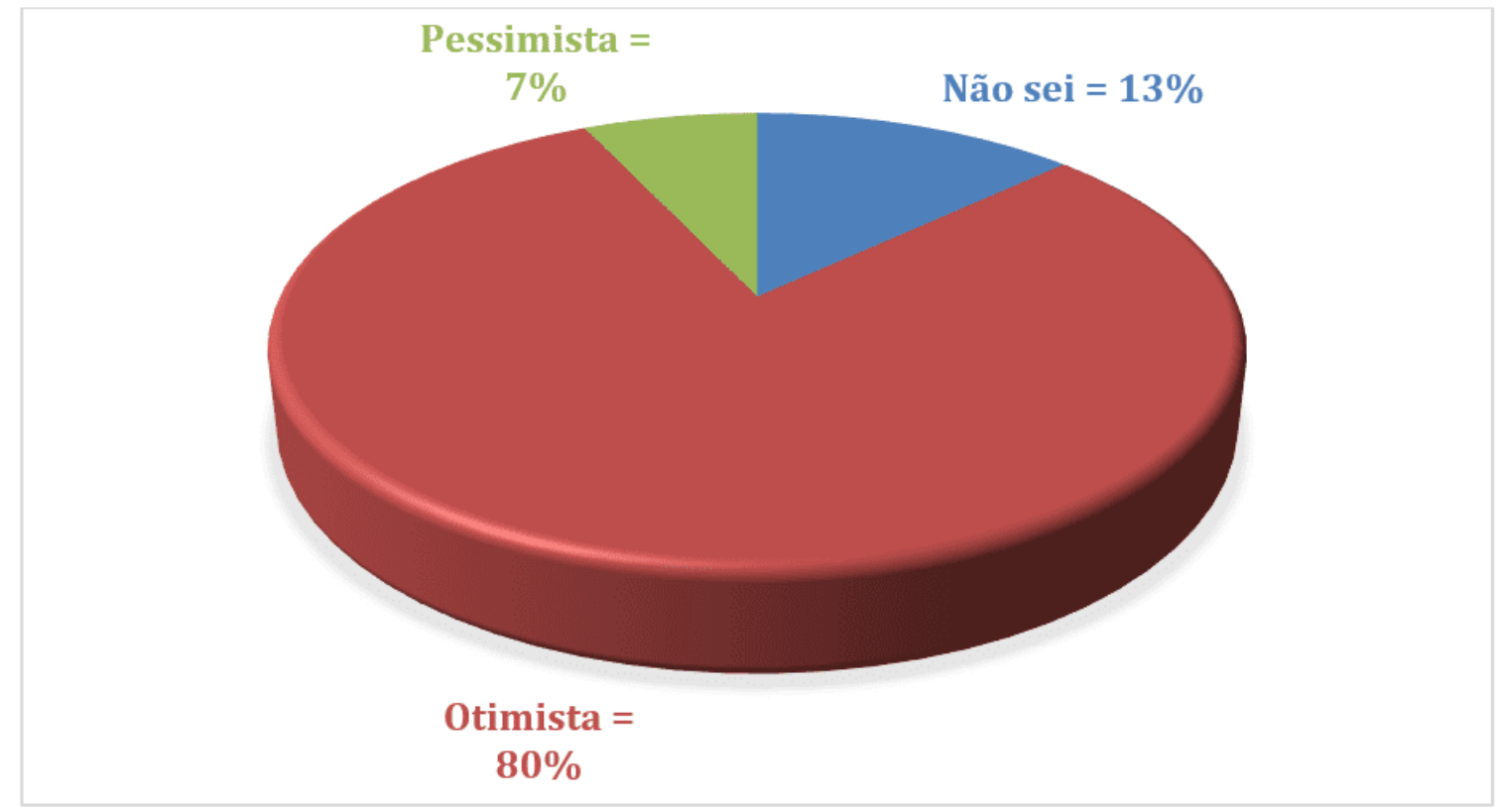

Fonte: Autor, 2020.

RC: 101267

Link de acesso: https://www.nucleodoconhecimento.com.br/administracao/desafiose-oportunidades 


\section{CONSIDERAÇÕES FINAIS}

Apesar de o momento exigir serenidade e sensibilidade, esta pesquisa mostrou um dado relevante. $64,2 \%$ das respostas foram dadas pelo público feminino, tal resultado realça uma tendência que é mundial.

O protagonismo feminino em um universo que por muito tempo era exclusivamente masculino, o da liderança. Seja em um ambiente doméstico, em procurar meios de angariar renda para manter a o sustento de sua família, seja em um ambiente corporativo, usando meios criativos de manter sua equipe ou empresa funcionando e até mesmo como regente de governo, a mulher mostra que tem maior sensibilidade em lidar com situações que exigem maior autocontrole e espírito coletivo.

Sendo assim, os desafios podem ser encarados de duas formas divergentes, positiva ou construtiva. Visualizar uma oportunidade de sair da zona de conforto e seguir em frente, vencendo os obstáculos (positiva) ou sentir medo, se intimidar e enxergar apenas as adversidades (negativas).

É preciso coragem (confiança e capacidade de agir de forma positiva e construtiva em momentos difíceis e de temor) e resiliência (aprender a se adaptar) para encarar e vencer um desafio.

A doença do COVID-19 está sendo um termômetro interessante em demonstrar como as pessoas estão enfrentando os desafios e lidando com as oportunidades durante essa pandemia e depois dela.

\section{REFERÊNCIAS}

CRISE. LÉXICO. Dicionário de Português Online. 2021. Disponível em: https://www.lexico.pt/crise/. Acesso em: 16 nov. 2021.

DESAFIO. LÉXICO. Dicionário de Português Online. 2021. Disponível em: https://www.lexico.pt/desafio/ Acesso em: 14 jun. 2020.

RC: 101267

Link de acesso: https://www.nucleodoconhecimento.com.br/administracao/desafiose-oportunidades 
FONSECA, J. J. S. da. Metodologia da Pesquisa Científica. Ceará: UECE Universidade Estadual do Ceará, 2002.

GESTÃO. DICIO. Dicionário Online de Português. Porto 7 Gaus: 2020. Disponível em: https://www.dicio.com.br/gestao/ Acesso em: 07 jun. 2020.

GIL, A. C. Como elaborar projetos de pesquisa. 5ª ed. São Paulo: Ed. Atlas, 2010.

LUECKE, R. Tomando Decisões. $1^{\text {a }}$ ed. Rio de Janeiro: Ed. Record, 2007.

OPORTUNIDADE. DICIO. Dicionário Online de Português. Porto: 7 Graus, 2020. Disponível em: https://www.dicio.com.br/oportunidade/ Acesso em: 14 jun. 2020.

PANDEMIA. LÉXICO, Dicionário de Português Online. 2021. Disponível em: https://www.lexico.pt/pandemia/. Acesso em: 16 nov. 2021.

REGIÃO SÃO JOSÉ DO RIO PRETO. Disponível em: http://www.cidadespaulistas.com.br/prt/cnt/08-sjdoriopreto.htm. Acesso em: 15 jun. 2020.

RICHARDSON, R. J. Pesquisa social: métodos e técnicas. 3aㅡ ed. São Paulo: Atlas, 1999.

Enviado: Março, 2021.

Aprovado: Novembro, 2021.

RC: 101267

Link de acesso: https://www.nucleodoconhecimento.com.br/administracao/desafios- 